Article

\title{
Biocompatibility and Electrical Stimulation of Skeletal and Smooth Muscle Cells Cultured on Piezoelectric Nanogenerators
}

\author{
Andreu Blanquer ${ }^{1} \mathbb{D}^{D}$, Oriol Careta ${ }^{1}$ (D), Laura Anido-Varela ${ }^{1}$, Aida Aranda ${ }^{2}$, Elena Ibáñez ${ }^{1}$, Jaume Esteve ${ }^{2}$, \\ Carme Nogués $1, * \mathbb{D}$ and Gonzalo Murillo ${ }^{2, *(\mathbb{D})}$
}

1 Departament de Biologia Cel.lular, Fisiologia i Immunologia, Facultat de Biociencies, Universitat Autonoma de Barcelona, 08193 Bellaterra, Barcelona, Spain; Andreu.BlanquerJerez@fgu.cas.cz (A.B.); oriol.careta@uab.cat (O.C.); laura.anidovarela67@gmail.com (L.A.-V.); elena.ibanez@uab.cat (E.I.)

2 Instituto de Microelectrónica de Barcelona, IMB-CNM (CSIC), Til·lers s/n, Campus UAB, 08193 Bellaterra, Barcelona, Spain; aida.aranda@e-campus.uab.cat (A.A.); jaume.esteve@imb-cnm.csic.es (J.E.)

* Correspondence: carme.nogues@uab.cat (C.N.); gonzalo.murillo@csic.es (G.M.); Tel.: +34-93-594-7700 (G.M.)

check for

updates

Citation: Blanquer, A.; Careta, O.;

Anido-Varela, L.; Aranda, A.; Ibáñez, E.; Esteve, J.; Nogués, C.; Murillo, G. Biocompatibility and Electrical Stimulation of Skeletal and Smooth Muscle Cells Cultured on Piezoelectric Nanogenerators. Int. J. Mol. Sci. 2022, 23, 432. https:// doi.org/10.3390/ijms23010432

Academic Editor: Agata Przekora

Received: 17 November 2021

Accepted: 28 December 2021

Published: 31 December 2021

Publisher's Note: MDPI stays neutral with regard to jurisdictional claims in published maps and institutional affiliations.

Copyright: (C) 2021 by the authors. Licensee MDPI, Basel, Switzerland. This article is an open access article distributed under the terms and conditions of the Creative Commons Attribution (CC BY) license (https:// creativecommons.org/licenses/by/ $4.0 /)$.

\begin{abstract}
Nanogenerators are interesting for biomedical applications, with a great potential for electrical stimulation of excitable cells. Piezoelectric $\mathrm{ZnO}$ nanosheets present unique properties for tissue engineering. In this study, nanogenerator arrays based on $\mathrm{ZnO}$ nanosheets are fabricated on transparent coverslips to analyse the biocompatibility and the electromechanical interaction with two types of muscle cells, smooth and skeletal. Both cell types adhere, proliferate and differentiate on the $\mathrm{ZnO}$ nanogenerators. Interestingly, the amount of $\mathrm{Zn}$ ions released over time from the nanogenerators does not interfere with cell viability and does not trigger the associated inflammatory response, which is not triggered by the nanogenerators themselves either. The local electric field generated by the electromechanical nanogenerator-cell interaction stimulates smooth muscle cells by increasing cytosolic calcium ions, whereas no stimulation effect is observed on skeletal muscle cells. The random orientation of the $\mathrm{ZnO}$ nanogenerators, avoiding an overall action potential aligned along the muscle fibre, is hypothesised to be the cause of the cell-type dependent response. This demonstrates the need of optimizing the nanogenerator morphology, orientation and distribution according to the potential biomedical use. Thus, this study demonstrates the cell-scale stimulation triggered by biocompatible piezoelectric nanogenerators without using an external source on smooth muscle cells, although it remarks the cell type-dependent response.
\end{abstract}

Keywords: stimulation; nanogenerators; muscle cells; piezoelectric; $\mathrm{ZnO}$; electroceutical; bioelectronics; nanosheets; biomedical; biocompatibility

\section{Introduction}

The development of smart materials for biomedical applications has become one of the most interesting research fields in recent years. Smart materials can be defined as materials that have one or more properties that can be changed in a controlled fashion by external stimuli, such as stress, temperature, moisture, $\mathrm{pH}$, and electric, magnetic or ultrasonic fields [1-5]. Piezoelectric materials are smart materials that are able to generate a voltage when mechanical stress is applied, and vice-versa. Among all piezoelectric materials known, $\mathrm{ZnO}$ has attracted much interest because of its versatility, unique properties and multiple applications, including microelectronics, biosensors and tissue engineering [6-8]. The potential use of $\mathrm{ZnO}$ in the biomedical field is wide, with a high range of structures, from bulk material to different types of nanoparticles. In fact, it is already used in healthcare and cosmetic applications [8]. ZnO has been classified as a generally recognized safe material by the Food and Drug Administration (FDA) of the United States. However, there is still controversy about the cytotoxic effect of $\mathrm{ZnO}$ nanostructures, with different results depending on cell types and nanostructures, which should be elucidated before their use in biomedical applications. 
Zinc is an essential micronutrient and a vital cofactor that plays an important role in tissue metabolism. It is indispensable in numerous $\mathrm{Zn}$-dependent proteins involved in transcriptional regulation, DNA repair and extracellular matrix regulation, among others [9]. Controlled low concentrations of $\mathrm{Zn}$ are present in the cytosol as free ions that have been identified as secondary messengers capable of interacting with proteins to regulate intracellular pathways. Therefore, the presence of low concentrations of $\mathrm{Zn}$ is beneficial to cells, although high concentrations could be harmful [10]. In this regard, the use of $\mathrm{Zn}$-based biodegradable materials is considered a good choice for tissue regeneration.

$\mathrm{ZnO}$ has been demonstrated to be a considerably good antibacterial material, which is an important property for very different kinds of biomedical applications. Several authors have investigated this antibacterial effect on Staphylococcus epidermidis and Staphilococcus aureus. Both types of bacteria could infect the patient during surgery when present in implants and medical devices. The infection and the consequent immunological response could result in implant failure, causing serious problems for the patient. Several authors have demonstrated a decrease in bacterial adhesion and a significant decrease in bacterial viability on $\mathrm{ZnO}$ samples [11,12].

Controversial results on mammalian cells' interaction with $\mathrm{ZnO}$ nanostructures and nanoparticles have been reported depending on the specific shape of $\mathrm{ZnO}$ structures and the cell type. Hydroxyapatite- $\mathrm{ZnO}$ composites with polished surfaces allowed cell attachment, spreading and proliferation of osteoblasts and fibroblasts [13]. Results for ZnO nanorods showed that adhesion and, thus, viability of anchorage-dependent cells was reduced, indicating that these substrates cannot be used for biomedical implants when cell adhesion is needed [14,15]. In contrast, $\mathrm{ZnO}$ nanoflowers improved mouse MC3T3-E1 osteoblast adhesion, proliferation and differentiation when compared with $\mathrm{ZnO}$ films, although cell adhesion and differentiation were higher on polystyrene control [16]. All these results suggest that $\mathrm{ZnO}$ biocompatibility may depend on its structure and, also, the specific cell type. In this regard, it is necessary to analyse each nanostructure with the cell type of choice, according to the potential application, before considering its use as an implant or device candidate.

Nowadays, nanostructured $\mathrm{ZnO}$ is very popular for its application as piezoelectric nanogenerators (NGs). Millimetre-scale NGs have already been used for biological applications, including sensors and generators. However, NGs have also a great potential for electrical stimulation, at the cell scale, of excitable cells like osteoblasts, neurons and muscle cells [17]. In a previous paper, we demonstrated the cytocompatibility of $\mathrm{ZnO}$ nanosheets (NSs) on osteoblasts and macrophages, and their use as NGs to induce a cellular response to the local electric fields generated by the piezoelectric NSs. The inherent forces produced by the cells were able to induce a piezopotential without the use of external stimulation [18]. Electric stimulation of different cell types has an important effect on cell regeneration and metabolism. Muscle cells respond to electric fields and induce the contraction of muscle tissue. Thus, the local electric field generated by $\mathrm{ZnO}$ NSs would potentially improve the regeneration and rehabilitation of muscle tissue, with several future applications in chronic illnesses such as muscle atrophy, wasting and aging $[19,20]$.

In this study, we analyse the potential application of ZnO NSs on two muscle cell lines, one derived from mouse skeletal muscle and the other from rat smooth muscle. Both cell types are electrically excitable cells. We studied the cytocompatibility of ZnO NSs and the NGs-cells interaction by analysing cell viability, morphology, cytoskeleton distribution and proliferation over time. In addition, we studied the effect of electrical fields generated by the NGs on cell response by measuring intracellular calcium changes.

\section{Results}

\subsection{NG Characterization and Zn Ions Release over Time}

The grown ZnO NSs, which form the NG array on the AlN-coated coverslip, showed an optimized aspect ratio to be used for cell stimulation, with a mean thickness of $23 \pm 7 \mathrm{~nm}$ (Figures $1 \mathrm{~A}-\mathrm{C}$ and S1). Due to the reduced thickness of the AlN layer and the ZnO NSs, 
the resulting glass coverslips, once covered with the NG array, are translucent, facilitating the optical microscope inspection. In addition, the wurtzite crystal structure and preferential growth along (002) orientation were validated with X-ray diffraction (XRD) analysis (Figure 1D). An energy-dispersive spectroscopy (EDS) analysis confirmed the presence of $\mathrm{Zn}$ and $\mathrm{O}$ on the NS composition before immersion in cell culture medium (Figure 1E). The amount of $\mathrm{Zn}$ ions released from the NSs after immersion in the cell culture medium is shown in Figure 1F. Zn ions quantification using inductively coupled plasma mass spectrometry (ICP-MS) indicated a time-dependent dissolution, with a progressive increase over time. The quickest release was observed after 3 days in culture, reaching a concentration of $4.5 \mu \mathrm{g} \mathrm{mL}{ }^{-1}$ of $\mathrm{Zn}$ in a volume of $1 \mathrm{~mL}$. Zn concentration in the culture medium increased to $5.4 \mu \mathrm{g} \mathrm{mL}^{-1}$ after 7 days, reaching $6.3 \mu \mathrm{g} \mathrm{mL} \mathrm{m}^{-1}$ after 21 days.
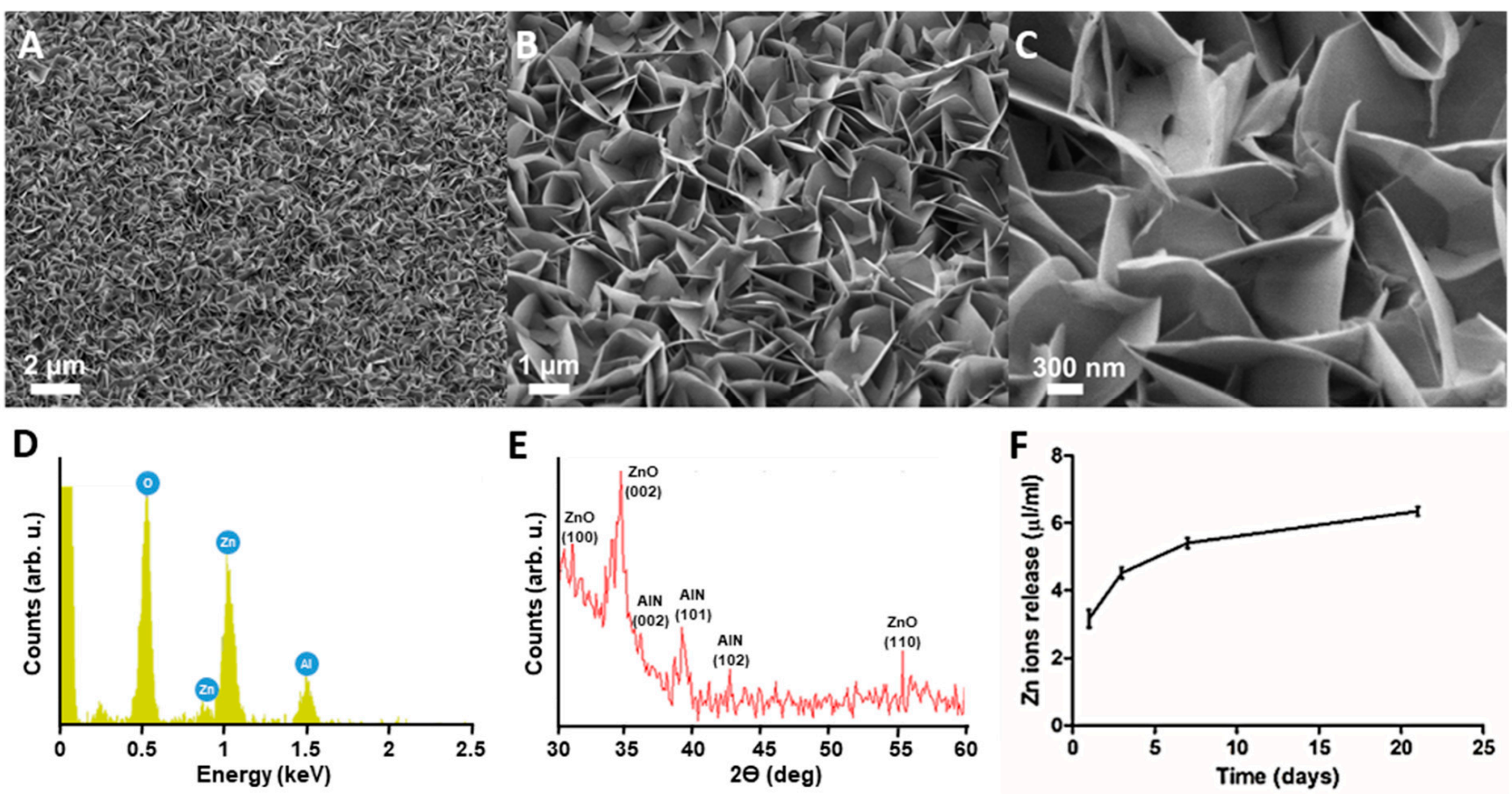

Figure 1. Characterization of ZnO NG arrays. SEM images of NSs grown for $9 \mathrm{~h}$ at $80{ }^{\circ} \mathrm{C}$ over an AlN layer of $100 \mathrm{~nm}$ at different amplification magnitudes: $1 \mathrm{KX}, 5 \mathrm{KX}$ and $20 \mathrm{KX}(\mathrm{A}-\mathrm{C})$; XRD measurement showing the high crystallinity of the NSs and the preferential orientation along (002) (D); Measurement EDS at the surface of the NSs, showing the presence of $\mathrm{Zn}, \mathrm{O}$ and $\mathrm{Al}$ (E). Concentration of $\mathrm{Zn}$ ions released from the $\mathrm{ZnO}$ NSs array over time in culture medium (F).

\section{2. $\mathrm{ZnO}$ Cytocompatibility for Smooth Muscle Cells}

Cytocompatibility of ZnO NG arrays for smooth muscle (A7r5) cells was analysed in terms of several biological parameters such as cell viability, adhesion, morphology and proliferation. Cell viability was analysed by quantifying the number of live cells using the Live/Dead kit, presenting live cells with esterase activity in green and dead cells in red (Figure 2A). The percentage of live cells was higher than $88 \%$, without significant differences when compared with the same cells grown on glass coverslips (control sample) (Figure 2B). In addition, no significant differences were found in the initial number of cells adhered and the mean spreading area of the cells after $24 \mathrm{~h}$ in culture between A7r5 cells growing on ZnO NG arrays and glass coverslips (Figure 2C,D). 

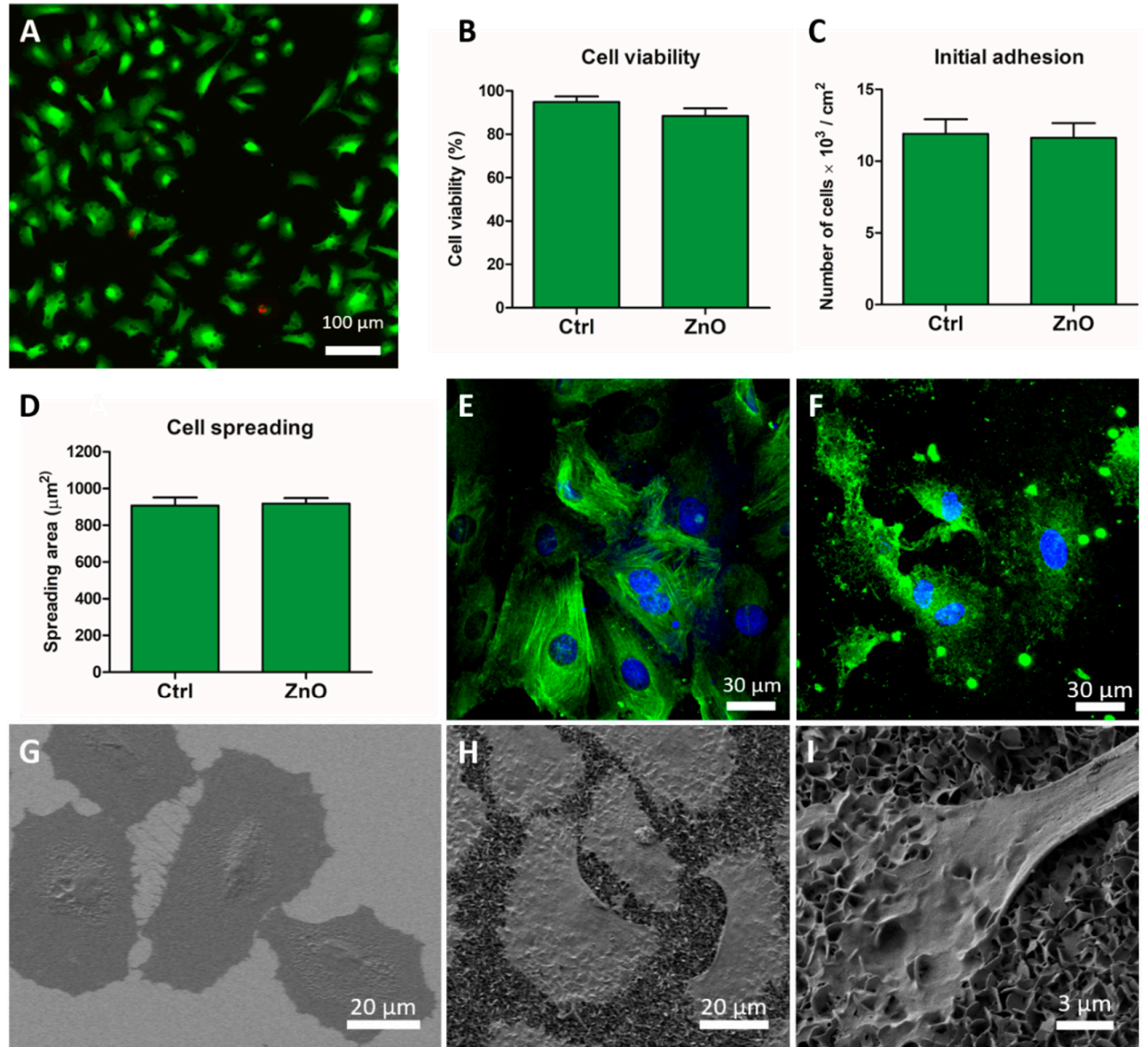

Figure 2. Smooth muscle (A7r5) cells grown on ZnO NG arrays. (A) Live (green) and dead (red) A7r5 cells cultured on ZnO NG array. (B) Percentage of viable A7r5 cells after $24 \mathrm{~h}$ in culture on ZnO NG arrays and glass coverslip (Ctrl), evaluated using Live/Dead viability/cytotoxicity kit. (C) Number of adhered cells and (D) mean spreading area of cells after $24 \mathrm{~h}$ in culture on $\mathrm{ZnO}$ NG arrays and glass coverslip (Ctrl). Confocal images of $\alpha$-smooth muscle actin immunodetection (green) and nuclei (blue) of cells growing on glass coverslip (E) and ZnO NG arrays (F) for $24 \mathrm{~h}$. SEM images of well-spread A7r5 cells on glass coverslip (G) and ZnO NG arrays (H,I) for 24 h. 2.3. ZnO cytocompatibility for skeletal myoblasts.

A7r5 cells' interaction with ZnO NG arrays and the morphology of A7r5 growing on $\mathrm{ZnO} \mathrm{NG}$ array were analysed after $24 \mathrm{~h}$ in culture using confocal laser scanning microscope (CLSM) and scanning electron microscope (SEM). Immunofluorescence analysis of $\alpha$ smooth muscle actin showed different distribution of actin fibres in A7r5 cells grown on ZnO NG arrays and glass coverslip. As shown in Figure 2E,F, cells grown on coverslip presented well-defined actin fibres crossing the cell from end to end, whereas cells grown on a $\mathrm{ZnO}$ NG array presented shorter actin bundles adapted to the topography of the NSs. However, cell spreading indicated that cells were well adhered to ZnO NSs without disturbing cell growth, allowing a close interaction between cells and NGs. A similar well-spread morphology was observed for cells growing on the ZnO NG arrays using SEM. Cell morphology analysis by SEM indicated that cells grown on a ZnO NG array and glass coverslip displayed a polygonal shape and a flattened morphology (Figure 2G,H), in close contact with the NGs (Figure 2I).

The effect of $\mathrm{ZnO}$ NGs on skeletal muscle (C2C12) cells was analysed in terms of cell viability, adhesion, morphology and proliferation, as for the smooth muscle cells. In addition, we analysed myotubes formation by $\mathrm{C} 2 \mathrm{C} 12$ cells fusion on the $\mathrm{ZnO}$ NG array.

Quantification of live cells using the Live/Dead kit showed that the viability of C2C12 cells growing on $\mathrm{ZnO} \mathrm{NG}$ arrays was higher than 98\% (Figure 3A), and no significant 
differences were observed between $\mathrm{ZnO}$ samples and glass coverslip (Figure 3B). Statistically significant differences were found in the initial number of cells adhered after $24 \mathrm{~h}$, being higher on the ZnO NG arrays $\left(64 \pm 4 \times 10^{3}\right.$ cells $\left./ \mathrm{cm}^{2}\right)$ compared to glass coverslip $\left(43 \pm 4 \times 10^{3}\right.$ cells $\left./ \mathrm{cm}^{2}\right)$ (Figure $3 \mathrm{C}$ ). However, the mean spreading area of cells was significantly reduced for cells growing on $\mathrm{ZnO} N G$ arrays $\left(351 \pm 30 \mu \mathrm{m}^{2}\right)$, when compared to cells growing on glass coverslip (591 $\left.\pm 49 \mu \mathrm{m}^{2}\right)$ (Figure 3D).
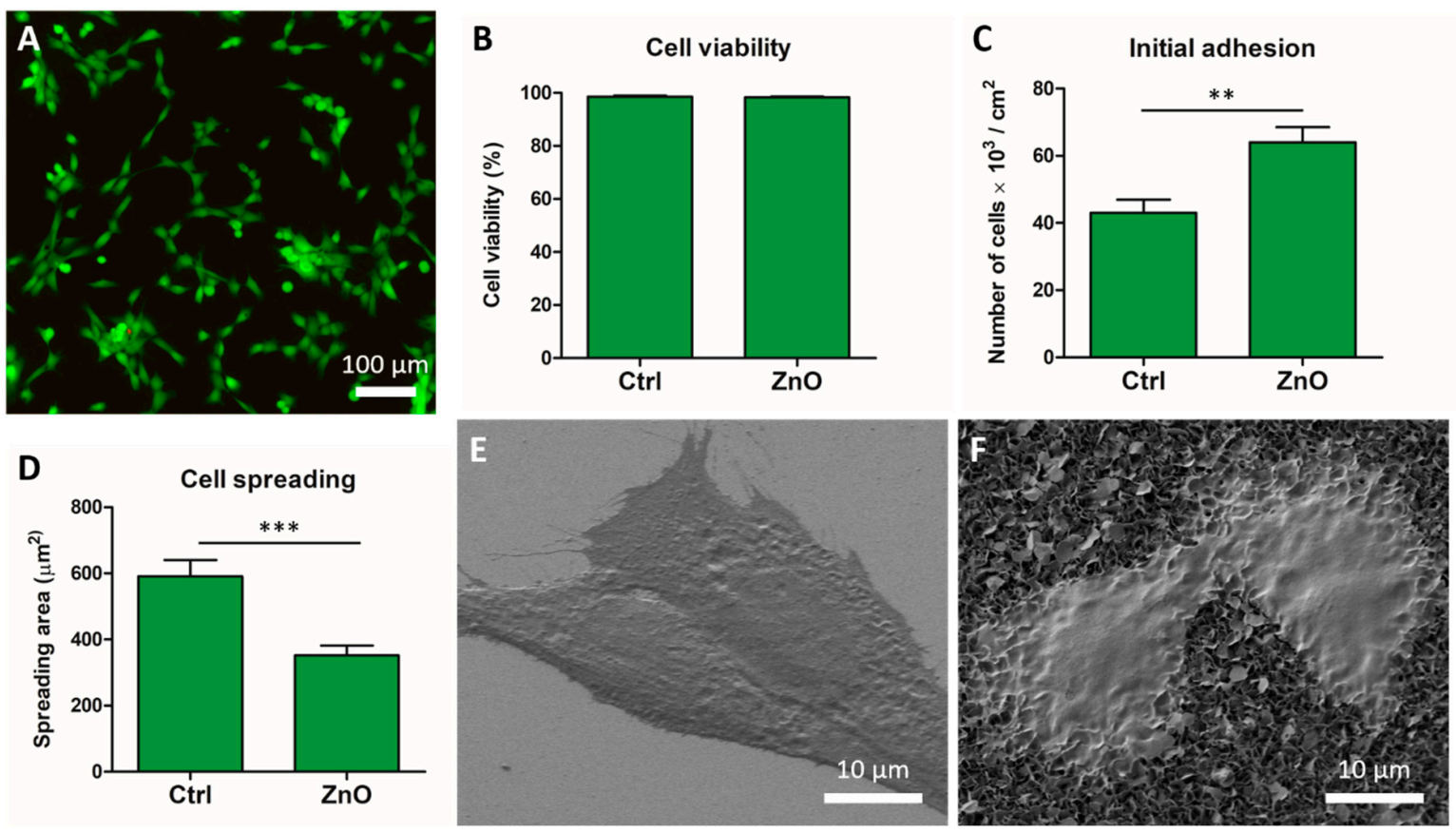

Figure 3. Skeletal myoblasts (C2C12) cells grown on ZnO NG arrays. (A) Live (green) and dead (red) C2C12 cells cultured on ZnO NG array. (B) Percentage of live cells after 24 h growing on ZnO NG arrays and glass coverslips (Ctrl), evaluated using Live/Dead viability/cytotoxicity kit. (C) Number of adhered cells and (D) mean spreading area of cells after $24 \mathrm{~h}$ in culture on $\mathrm{ZnO}$ NG arrays and glass coverslip (Ctrl). Statistically significant differences are marked by two asterisks $(p<0.01)$ or three asterisks $(p<0.001)$. SEM images of $\mathrm{C} 2 \mathrm{C} 12$ cells morphology on glass coverslip (E) and ZnO NG arrays (F) after $24 \mathrm{~h}$ in culture.

\subsection{Cell Morphology}

Cell morphology was evaluated using SEM after $24 \mathrm{~h}$ and 7 days in culture. After $24 \mathrm{~h}$, individualized $\mathrm{C} 2 \mathrm{C} 12$ cells showed a well-spread morphology on both $\mathrm{ZnO}$ NG array and glass coverslip, although cells growing on control glass seemed to be wider, as expected for the spreading area measurements (Figure 3E,F). Cytoplasmic extensions were visible, with a close interaction with $\mathrm{ZnO} N G$ arrays. After 7 days, a monolayer of cells was observed covering the whole $\mathrm{ZnO} \mathrm{NG}$ array and differentiated myotubes were also observed (Figure 4A).

Stress fibres distribution after 7 days in culture was analysed using CLSM. C2C12 cells showed clear stress fibres, without evident differences between $\mathrm{ZnO}$ NG arrays and coverslip samples (Figure 4B,C).

After 7 days in culture with the differentiation medium, it was possible to observe the fusion of several cells forming myotubes on both samples. To confirm that the structures observed were myotubes, the presence of sarcomeric $\alpha$-actinin, a component of Z-disk in differentiated skeletal muscle myotubes, was analysed. Images showed that $\alpha$-actinin were evident in differentiated myotubes in both substrates, without clear differences between them. Longitudinal myofilament bundles crossing the whole cell were detected (Figure $4 \mathrm{D}, \mathrm{E}$ ). In addition, a monolayer of undifferentiated myoblasts without $\alpha$-actinin labelling or diffused signal were visible. 

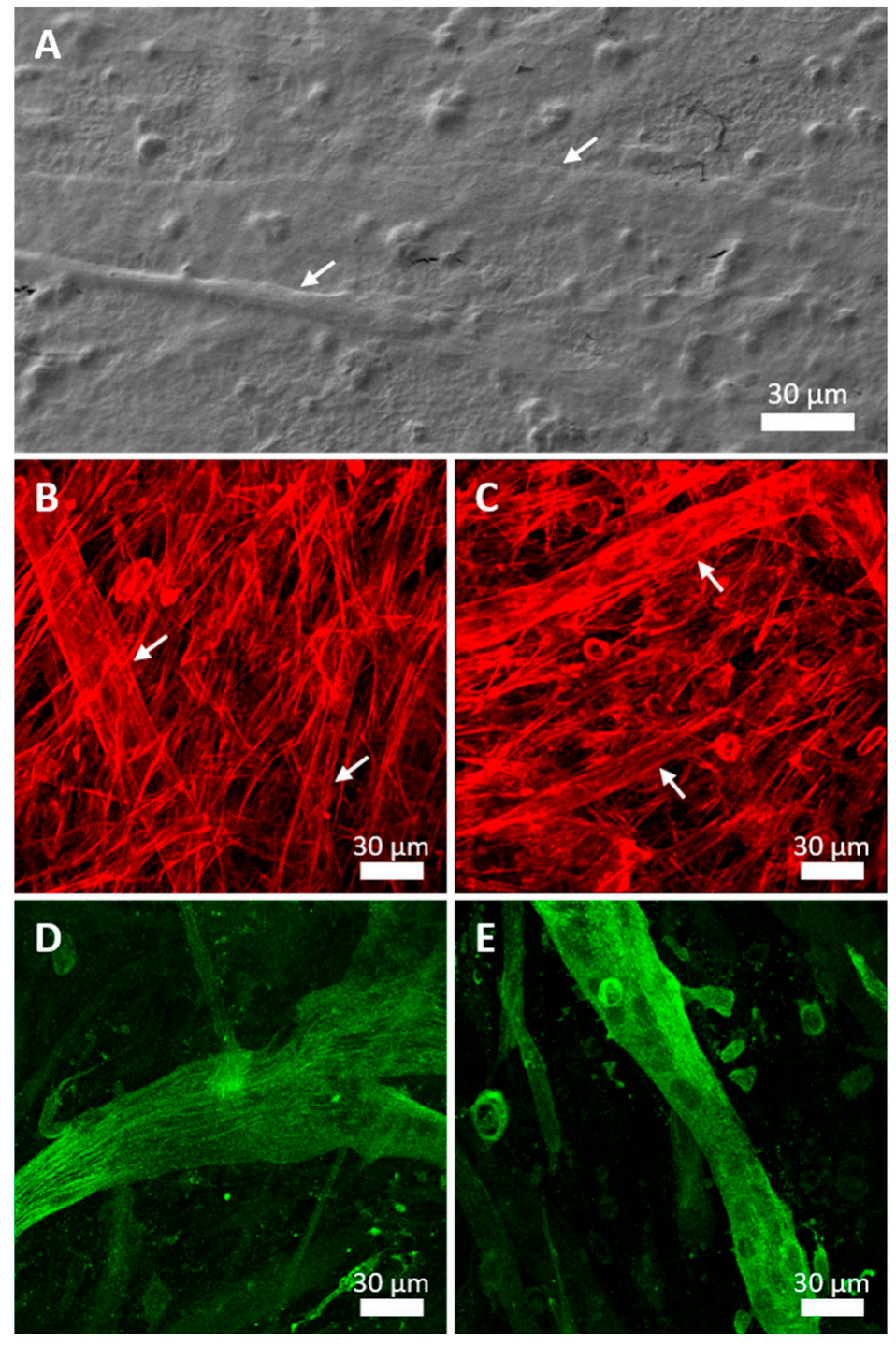

Figure 4. SEM images of differentiated $\mathrm{C} 2 \mathrm{C} 12$ cell after 7 days growing on ZnO NG arrays (A). CLSM images of skeletal myoblasts (C2C12) cells differentiated after 7 days in culture on glass coverslip (B,D) and ZnO NG arrays (C,E). Stress fibres immunodetection is shown in red (B,C) and $\alpha$-actinin immunodetection is shown in green $(\mathbf{D}, \mathbf{E})$. Skeletal muscle myotubes (arrows) were formed after 7 days in culture on both samples.

\subsection{Immunological Response}

To find out whether the $\mathrm{ZnO}$ NG arrays activate the secretion of inflammatory cytokines, we analysed the presence of six cytokines involved in inflammation using the cytometric bead array (CBA) test. Although all six cytokines quantified are important in the inflammatory response, each one plays a different role and the secretion by macrophages could be different. In general, IL-8, IL-12p70, IL-6, IL-1 $\beta$ and TNF are considered proinflammatory cytokines, whereas IL-10 is considered an anti-inflammatory cytokine. Quantification results showed that no significant increase in cytokines concentration was observed after $5 \mathrm{~h}$ and $24 \mathrm{~h}$ of macrophages culture on the $\mathrm{ZnO}$ NG array (Figure 5). On the contrary, the presence of lipopolysaccharide (LPS) in the cell culture medium stimulated the secretion of all cytokines tested. 
A

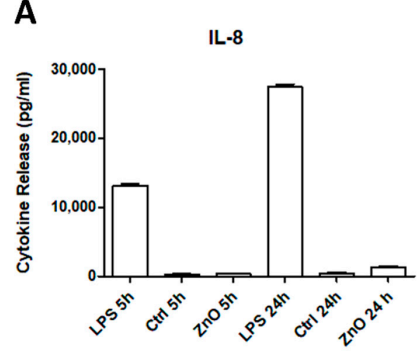

D

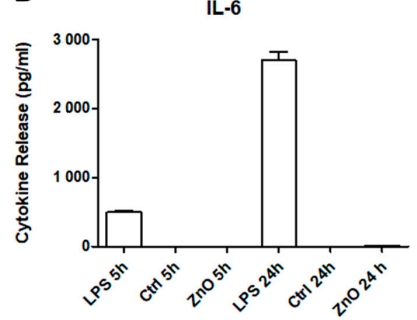

B

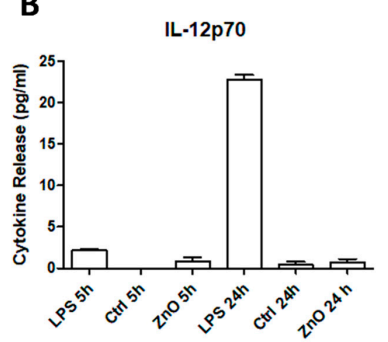

E

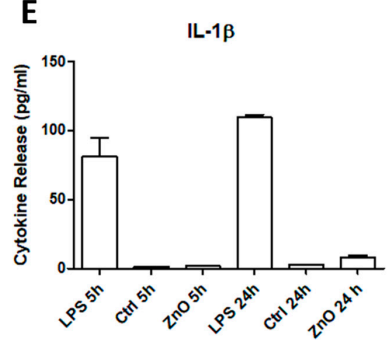

C

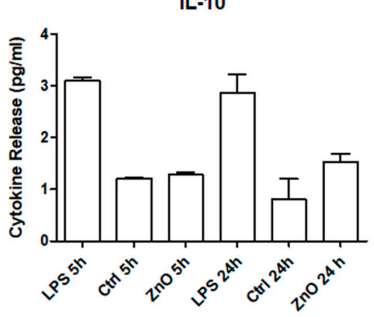

$\mathbf{F}$

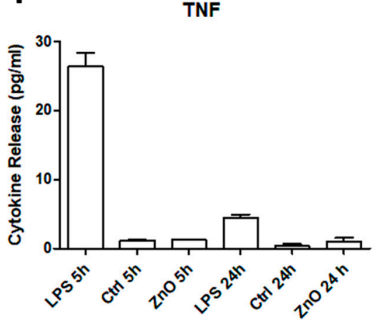

Figure 5. Cytokine release by macrophages analysed by the CBA test after 5 and $24 \mathrm{~h}$ of culture. Six types of cytokines involved in inflammation, IL-8 (A), IL-12p70 (B), IL-10 (C), IL-6 (D), IL-1ß (E) and TNF (F), are shown in the presence of lipopolysaccharide (LPS, positive control), ZnO NG array, and a negative control.

\subsection{Intracellular Calcium Changes}

Calcium is a second messenger involved in several intracellular pathways, such as muscle contraction. Skeletal muscle cells and smooth muscle cells exposed to electrical stimulation undergo changes in intracellular calcium levels (Figure 6A,B), which induces muscle contraction.
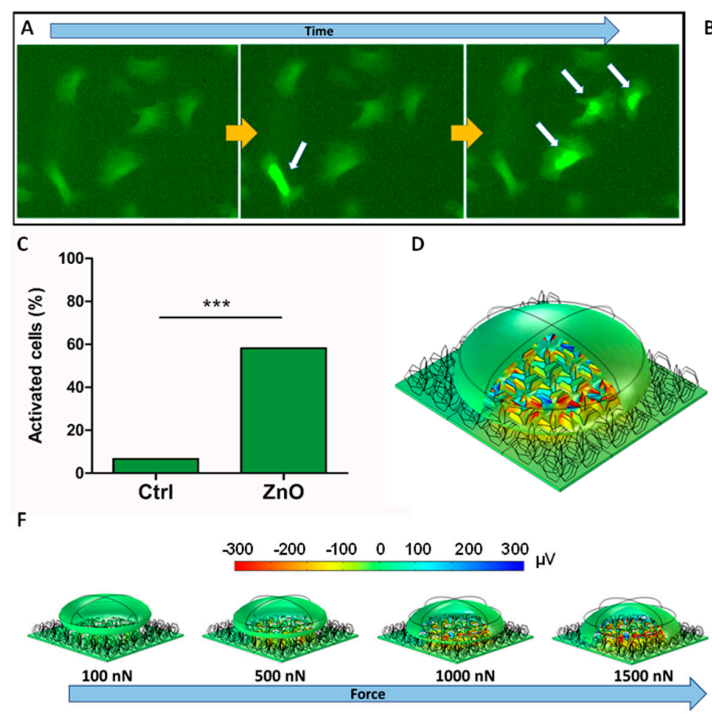
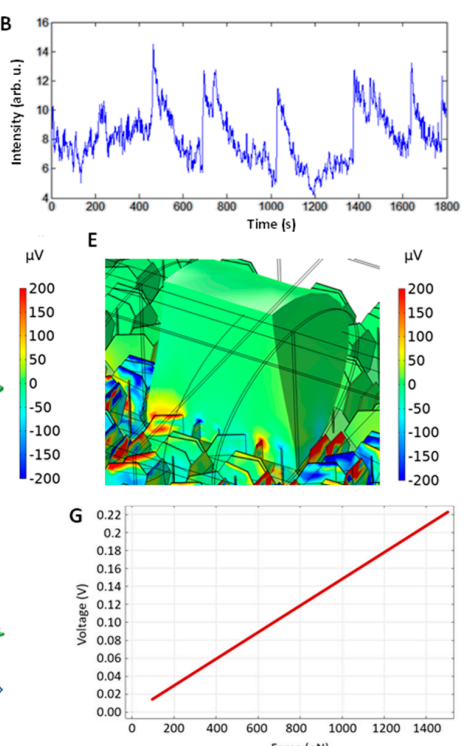

Figure 6. Frames of time-lapse video showing florescence due to calcium influxes in smooth muscle (A7r5) cells (A). Intensity of fluorescence indicating calcium influx in a certain A7r5 cell at timepoints: $5 \mathrm{~min}, 6 \mathrm{~min}$ and $7 \mathrm{~min}$ (B). Percentage of activated smooth muscle (A7r5) cells which undergo changes in intracellular calcium concentration (C); statistically significant differences are marked by three asterisks $(p<0.001)$. COMSOL simulations with the piezopotentials generated by a smooth muscle cell (D) and cylinder-like cell (E), corresponding to a sarcomere of a skeletal muscle fibre, when exerting a force of $1 \mu \mathrm{N}$. Simulation of smooth muscle cell shape and electric potential distribution (F) and values of the potential at the membrane $(\mathbf{G})$ for different muscle forces. 
Results in smooth muscle cells after $24 \mathrm{~h}$ in culture showed that A7r5 cells grown on the ZnO NG array presented $58 \%$ of cells with calcium transients, whereas only $7 \%$ of cells presented calcium transients on glass coverslip (Figure 6C). By contrast, no significant differences in intracellular calcium changes were detected between $\mathrm{C} 2 \mathrm{C} 12$ cells grown for 7 days on ZnO NG arrays and glass coverslip (Video S1 in Supporting Information).

\subsection{Finite Element Modelling}

Finite element modelling (FEM) has been used to estimate the piezopotential that the NG array produces when cells adhere to the top of the material (Figure 6D). The range of forces which cells exert when they attach and move goes from $0.1 \mathrm{nN}$ to $100 \mathrm{nN}$ [21-23]. In case of muscle cells, the forces produced can be in the $\mu \mathrm{N}$ range [24]. As a representative value, a force of $1 \mu \mathrm{N}$ perpendicular to the top of the cell surface has been applied for a smooth muscle cell already adhered (flattened shape, e.g., day 7 of culture). A variety of values of piezopotentials for each NSs positioned not perpendicular to the membrane can be observed, being the maximum voltages around $+200 \mu \mathrm{V}$ and $-200 \mu \mathrm{V}$ in the cell membrane. Considering the absolute value of the piezopotential generated for each NG, there are no important differences in magnitude. This voltage depends on the cell force, and the NS size. The size of the NSs has been optimized for cell stimulation by inherent cell forces, obtaining the best result for $9 \mathrm{~h}$ of growth at $80^{\circ} \mathrm{C}$ using an AlN seed layer of $100 \mathrm{~nm}$ (unpublished work). In addition, a model of a myotube with a stretching force of $1 \mu \mathrm{N}$, perpendicular to the cross sections of the cylinder, has been simulated. Figure $6 \mathrm{E}$ shows the voltage in a specific region that represents a sarcomere as unit of contraction of a skeletal muscle fibre. As can be shown, the force in that direction generates similar voltages in the cell membrane, ranging from $+200 \mu \mathrm{V}$ to $-200 \mu \mathrm{V}$, although higher voltages can be obtained along the NSs. However, due to the overall charge cancelation, the transversal potential difference between both cross-sectional faces is lower than $1.13 \mu \mathrm{V}$. This potential is inferior to the local potentials found for the smooth cells, where the overall direction of the potential difference seems not to be critical for the cell activation. Figure $6 \mathrm{~F}, \mathrm{G}$ shows the simulations of a smooth muscle cell with the electric potential distribution and the values of the electric potential at the membrane for different muscle forces. The electric potential values go from around $-300 \mathrm{mV}$ to $300 \mathrm{mV}$ at the cell membrane, for normal cell forces in the range of the $100 \mathrm{nN}$ to $1500 \mathrm{nN}$.

\section{Discussion}

$\mathrm{ZnO}$ nanostructures have attracted remarkable attention as smart piezoelectric materials for biomedical applications. However, several authors have reported controversial results on the biocompatibility of different $\mathrm{ZnO}$ nanostructures and nanoparticles with different cell types. In this regard, the morphology of $\mathrm{ZnO}$ plays an important role for cytotoxicity. In the present work, ZnO NG arrays based on ZnO NSs were fabricated for biomedical purposes. The hydrothermal method to grow NSs was optimized to be performed on glass coverslips and to obtain a thin layer of NSs with the optimal NS thickness to ensure the piezoelectric effect. All the samples obtained presented the same area and were translucent enough to visualize the cells under an optical microscope.

On the other hand, biodegradability is another important property of $\mathrm{ZnO}$. New biodegradable devices have a great interest in tissue engineering, although degradable products should not cause undesirable effects. Su et al. (2018) reported that cytotoxicity of $\mathrm{ZnO}$ nanoparticles is mainly due to increased intracellular $\mathrm{Zn}$ ions as a result of $\mathrm{ZnO}$ solubility [10]. For this reason, we decided to quantify the concentration of $\mathrm{Zn}$ ions released from the ZnO NSs array over time. The results obtained showed that concentrations reached $5.4 \mu \mathrm{g} \mathrm{mL} \mathrm{gL}^{-1}$ and $6.2 \mu \mathrm{g} \mathrm{mL}^{-1}$ after 7 and 21 days, respectively. It has been stated that concentrations lower than $27 \mu \mathrm{g} \mathrm{mL} \mathrm{m}^{-1}$ of $\mathrm{Zn}$ ions allowed human neuroblastoma cells proliferation [25]. Specific results for smooth muscle cells demonstrated that less than

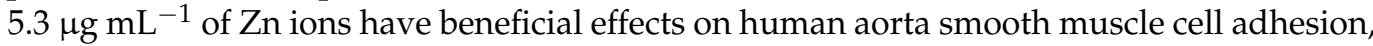
spreading, viability, proliferation and migration [26]. However, different smooth muscle 
cells from different species respond differently, showing inhibited proliferation of smooth muscle cells from carotid artery of Wistar rats at $2.5 \mu \mathrm{g} \mathrm{mL}^{-1}$ of $\mathrm{Zn}$ ions or significantly reduction of human prostatic smooth muscle cells proliferation above $16.7 \mu \mathrm{g} \mathrm{mL}{ }^{-1}$ [27]. Taking into account these previous results, we expected that the concentration of $\mathrm{Zn}$ ions release from $\mathrm{ZnO}$ NSs array would not reduce the viability of smooth muscle cells and skeletal muscle cells. To elucidate this point, we analysed the viability, adhesion, proliferation and differentiation of the two muscle cell types on $\mathrm{ZnO} \mathrm{NG}$ arrays up to 7 days in culture. In both cell types, cells presented high viability and were able to proliferate and differentiate on $\mathrm{ZnO} N G$ arrays. These results are in agreement with our previous results when analysing cytotoxicity of $\mathrm{ZnO}$ NG arrays for Saos-2 cells and macrophages [18]. Moreover, the $\mathrm{Zn}$ ions released from the $\mathrm{ZnO}$ NG arrays did not have any negative effect either on smooth muscle cells or on skeletal muscle cells.

To go further in the analysis of biocompatibility, we analysed the immunogenic response to $\mathrm{ZnO}$ NG arrays. The biological response to corrosion products from the devices can be responsible for inflammatory reactions and can induce the formation of a non-adherent fibrous capsule surrounding the device, which could end in chronic inflammation [28]. We analysed the release of six cytokines involved in inflammation by macrophages when cultured in the presence of $\mathrm{ZnO} N G$ arrays and controls. Results indicated that after an incubation of 5 and $24 \mathrm{~h}$ with $\mathrm{ZnO}$ NG arrays, no significant amounts of inflammatory cytokines were secreted compared with the negative control. However, the secretion of cytokines was high when macrophages were incubated with LPS as positive control. It has been reported that the inflammatory response activation depends on the particle and ion concentration. In this regard, we can correlate the ions' release after $24 \mathrm{~h}$ with the inflammatory response and assume that a concentration of $3.1 \mu \mathrm{g} \mathrm{mL} L^{-1}$ of $\mathrm{Zn}$ ions does not activate it.

Surface topography can modulate cell adhesion, morphology and the interaction between cells and material. In addition, topography and stiffness could influence the differentiation of cells on biomaterials and devices. The results showed that both types of muscle cells adhered well to ZnO NSs, with the cytoskeleton adapted to the topography and cytoplasmic prolongations connected to NSs. The close interaction between cells and the NGs is necessary for the induction of a piezoelectric effect. In the case of C2C12 cells, we found an increase in the number of cells initially adhered to ZnO NG arrays compared to glass coverslips, although the spreading area of the adhered cells was lower in $\mathrm{ZnO}$ NG arrays. The $\mathrm{C} 2 \mathrm{C} 12$ cells are able to proliferate as soon as they adhere to a surface and the population doubling time is very short. Therefore, due to the proliferative rate of $\mathrm{C} 2 \mathrm{C} 12$ cells, no differences were observed after 7 days in culture. Besides the proliferation, skeletal muscle cells need to differentiate to create functional myotubes. After 4 days, myoblasts fuse in response to the differentiation medium, producing syncytia with several nuclei [29]. Ciofani et al. (2012) analysed the differentiation of H9c2 cells on $\mathrm{ZnO}$ nanowires as a model for skeletal muscle cells, and observed that cells displayed a disordered arrangement, without showing the typical tubular shape of H9c2 myotubes [30]. They suggested that the stiffness or the nanotopography of $\mathrm{ZnO}$ nanowires was cause for the prevention of myotubes formation. By contrast, our results showed that $\mathrm{C} 2 \mathrm{C} 12$ cells were able to differentiate and form myotubes on $\mathrm{ZnO}$ NGs, similar to those formed when grown on control samples. The formation of myotubes is a necessary step for further functionality of muscle cells, including myotubes contraction.

Both smooth muscle cells and skeletal muscle cells are able to respond to electric stimulation by voltage-gated calcium channels (VGCC). Plasma membrane depolarization caused by the electric fields opens the VGCC and, subsequently, increases the intracellular calcium concentration. In our study, we analysed the intracellular calcium changes in cells grown on the $\mathrm{ZnO} \mathrm{NG}$ arrays and found different results depending on the cell type tested. Intracellular calcium transients were detected in smooth muscle cells, showing a significant increase on $\mathrm{ZnO} N G$ arrays (i.e., $58 \%$ of activated cells compared to $7 \%$ in the control), whereas no differences were detected in skeletal muscle cells. Results suggest 
that piezoelectric $\mathrm{ZnO}$ NG arrays are able to generate a local electric field that activates the smooth muscle cells. These results are in agreement with our previous results on osteoblasts, where we hypothesized that the mechanical stress produced by cell adhesion is responsible for their own electromechanical stimulation [18]. Similar results were also observed in piezoelectric PVDF nanofiber scaffolds [31]. In addition, FEM simulations also validate the piezoelectric stimulation of smooth muscle cells, that is, the NGs can create local piezopotential distributions, allowing a local activation of the VGCC and the corresponding calcium influx. The simulated voltages generated by the NGs range from around $-300 \mathrm{mV}$ to $300 \mathrm{mV}$ at the cell membrane, which are values theoretically high enough to activate the VGCCs at the cell membrane.

By contrast, skeletal muscle cells did not show any effect of the $\mathrm{ZnO} \mathrm{NG}$ arrays regarding intracellular calcium changes. These results were unexpected, but several factors may be responsible for the lack of cell stimulation. In the literature, several authors have studied the effect of electrical stimulation on C2C12 cells by analysing a wide range of electric fields, frequency and timing of the stimulation. All of them agree that electrical pulses with certain periodicity are necessary to mimic the physiological stimulation in vitro, and that they allow the creation of functional skeletal muscle tissues [20,32]. Indeed, single myoblasts respond to electromagnetic fields by modulation of the intracellular calcium [33]. The effect of electromagnetic fields to myoblasts could be responsible for the creation of functional myotubes. On the other hand, multinucleated myotubes in physiological tissues present a highly unidirectional orientation, which is necessary to produce contracting forces. In vitro, myotube formation loses the natural organization and the myotubes appear randomly distributed. It seems that the lack of cell alignment may alter the functionality of skeletal muscle [34]. In our study, we hypothesized that adherent cell forces would be able to mechanically stress the NGs and induce a local electric field to stimulate muscle cells. Therefore, no external energy sources were used and the potential electric stimulation was generated randomly by the different $\mathrm{ZnO}$ NGs of the array. In addition, a single myotube could be stimulated by several NGs at the same time and at different regions of the plasma membrane, depending on the area of the cell pressing on the $\mathrm{ZnO} \mathrm{NG}$ array during adhesion or movement. This random stimulation in different directions depending on the orientation of each NS could alter the contraction because of the lack of unidirectional electrical stimulation. The randomly generated electric fields by $\mathrm{ZnO}$ NGs was validated with the COMSOL simulations performed with a random NG array. As has been reported, the electric field direction is crucial for correct muscle contraction when an electric field is applied $[35,36]$. The myotube contraction is controlled by the direction of the electric field due to the highly anisotropic electrical properties of skeletal muscle. Moreover, electrical parameters such as frequency, pulse width and voltage amplitude should be controlled to stimulate the skeletal muscle contraction without electrochemical damage or toxicity. Therefore, to allow for a specific stimulation for this type of cells, we should use an NG array with aligned NSs along the perpendicular direction of the myotubes. Unfortunately, the hydrothermal method used for this work does not allow for this alignment. However, research using a micromachined piezoelectric material, such as PVDF, with aligned patterns at the nanoscale (e.g., using stamp or soft-lithography or reactive ion etching) is currently being conducted, with promising potential. In addition, it is possible to use ultrasound signals to wirelessly actuate the NGs in order to electrically stimulate the cells. The results provided by this work allow the study of a family of groundbreaking developments for a personalized and minimally invasive nanomedicine.

\section{Materials and Methods}

\subsection{NG Synthesis and Optimization}

NG arrays based on ZnO NSs were synthesised using a hydrothermal growth at mild conditions. In order to allow growth on the NS shape, a thin-film layer of $100 \mathrm{~nm}$ of AlN was deposited by using radio-frequency (RF) sputtering on top of glass coverslips. An aqueous solution containing hexamethylenetetramine (HMTA) and $\mathrm{Zn}\left(\mathrm{NO}_{3}\right)_{2}$ was 
introduced in an amber wide-mouth jar. The coated glass coverslips were placed in the jar, floating on the solution, with the AlN layer facing down. The jar was sealed and introduced in an oven at $80^{\circ} \mathrm{C}$ for $9 \mathrm{~h}$. Then, the coverslips were collected, rinsed in deionized water and ethanol and left to dry at room temperature (RT). The growth parameters (i.e., $80{ }^{\circ} \mathrm{C}$ for $9 \mathrm{~h}$ ) were optimized in order to improve the activation effect.

\subsection{NG Characterization}

The grown ZnO NSs on an AlN-coated coverslip were characterized using an SEM Zeiss Auriga at $3 \mathrm{kV}$ and a secondary electrons detector together with an energy-dispersive X-ray spectroscopy (EDS/EDX) detector. EDX measurements were obtained by applying a voltage of $5 \mathrm{kV}$. In addition, XRD analysis was obtained on a Bruker D8 Advance diffractometer $(\mathrm{CuK} \alpha, \lambda=1.5418 \AA$ ) with a bidimensional general area detector diffraction system (GADDS) detector. For this measurement, a $2 \theta$ angle ranging from $30^{\circ}$ to $60^{\circ}$, a voltage of $40 \mathrm{KV}$ and a current of $40 \mathrm{~mA}$ were used.

\subsection{COMSOL Simulation}

We used the piezoelectric physics of COMSOL to simulate the piezopotential generated by NGs based on hexagonal ZnO NSs. The ZnO NSs were created with a thickness of $30 \mathrm{~nm}$ and a height of $1000 \mathrm{~nm}$. A layer of $100 \mathrm{~nm}$ of AlN was used in the bottom surface. Mechanically, all the substrate was anchored. A force of $1 \mu \mathrm{N}$ was applied normally to the cell membrane. A tetrahedral mesh with adaptive size (i.e., coarse for cell, medium for substrate and fine for NSs) was used (Figure S2). The piezoelectric origin axes were carefully chosen for each NS, so that they were aligned along their respective c-axis.

\subsection{Zinc Ions Released from NGs}

In order to analyse the biodegradability of the ZnO NG arrays, the amount of zinc ions released from the NGs was quantified. ZnO NG arrays were sterilized in ethanol for $30 \mathrm{~min}$ and incubated with $1 \mathrm{~mL}$ of DMEM cell culture medium at standard conditions $\left(37{ }^{\circ} \mathrm{C}\right.$ and $\left.5 \% \mathrm{CO}_{2}\right)$. The culture medium was withdrawn after $24 \mathrm{~h}$ and after 3,7 and 21 days, and the zinc concentration was analysed by ICP-MS on an Agilent ICP-MS 7500ce equipment (Agilent Technologies, Santa Clara, CA, USA).

\subsection{Cell Lines}

Two different muscle cell lines were used to test the cytocompatibility of the ZnO NG arrays and to analyse the piezoelectric effect generated by them: C2C12 mouse skeletal myoblasts and A7r5 rat smooth muscle cells (both from ATCC). C2C12 cells were cultured under standard conditions in Dulbecco's modified Eagle medium (DMEM; Invitrogen) supplemented with 10\% foetal bovine serum (FBS; Thermo Fisher Scientific, Waltham, MA, USA). For myoblast differentiation, the growth medium was replaced by a differentiation medium containing DMEM supplemented with 10\% horse serum (Thermo Fisher Scientific) after $24 \mathrm{~h}$ of cells seeding. The differentiation medium was replaced each 2 days for 7 days. A7r5 cells were grown in DMEM supplemented with $10 \%$ FBS under standard conditions.

THP-1 monocyte cells were used to analyse the immunological response to the $\mathrm{ZnO}$ NG array. Monocytes were grown in an RPMI 1640 medium (Gibco) supplemented with $25 \%$ FBS in standard conditions. To differentiate monocytes into macrophages, 400,000 THP-1 cells were seeded into 24-well plates and treated with $0.16 \mu \mathrm{M}$ phorbol-12-myristate13-acetate (Sigma) for $72 \mathrm{~h}$. Then, the cells were washed and incubated in a fresh medium for $24 \mathrm{~h}$ before carrying out the experiments.

\subsection{Cell Viability Assay}

Direct cytotoxicity was evaluated by detecting the activity of intracellular esterases using the Life/Dead Viability/Cytotoxicity kit for mammalian cells (Invitrogen), according to the manufacturer's protocol. Briefly, ZnO NG arrays were cleaned and sterilized with absolute ethanol for at least $1 \mathrm{~h}$. Once sterilized, samples were transferred into 4-well 
culture plates and $1 \times 10^{5} \mathrm{C} 2 \mathrm{C} 12$ cells or $3 \times 10^{4} \mathrm{~A} 7 \mathrm{r} 5$ cells were seeded on top of each $\mathrm{ZnO} N G$ array and cultured for $24 \mathrm{~h}$. In parallel, the same number of cells were seeded on glass coverslips as control substrates. After $24 \mathrm{~h}$, cells were incubated with the kit and images from different regions of the samples were captured on an inverted epifluorescence microscope (Olympus IX7). Each experiment was performed in triplicate and a minimum of 300 cells were analysed per sample.

\subsection{Initial Cell Adhesion and Spreading Area of Cells}

To quantify the number of cells initially adhered on samples and the mean spreading area per cell, images previously captured for cell viability assay were used. The cell number was quantified using the cell counter plugin of Image J software. The spreading area was measured analysing fluorescent calcein using Image J software. For each experiment, at least 15 regions from 3 replicates were analysed.

\subsection{Cell Morphology Assay}

At the end of the cell viability assay, the same samples were prepared for SEM visualization. Cells grown on samples were rinsed twice in phosphate buffered saline (PBS), fixed in 4\% paraformaldehyde (PFA; Sigma) in PBS for $15 \mathrm{~min}$ at RT and rinsed twice in PBS. Then, the cells were dehydrated by ethanol at increasing concentrations $(50 \%, 70 \%, 90 \%$ and twice 100\%) for 8 min each and dried using hexamethyl disilazane (Electron Microscopy Science) for $15 \mathrm{~min}$. Finally, samples were mounted on special stubs and analysed using SEM Zeiss Auriga.

\subsection{Immunofluorescence Detection of Smooth Muscle Actin on A7r5 Cells}

Cytoskeleton distribution in A7r5 cells was analysed by detecting $\alpha$-smooth muscle actin ( $\alpha$-SMA), a specific protein of smooth muscle cells. A total of $6 \times 10^{4}$ cells were seeded on $\mathrm{ZnO}$ NG arrays and glass coverslip controls. After 7 days in culture, the cells were fixed in $4 \%$ PFA in PBS for $15 \mathrm{~min}$ at RT, and permeabilised and blocked with $0.5 \%$ Triton X-100, $0.2 \%$ sodium azide and 3\% goat serum in PBS for $30 \mathrm{~min}$ at RT. Then, the cells were incubated with mouse anti- $\alpha$-SMA IgG monoclonal-antibody (1:500; Sigma) overnight at $4{ }^{\circ} \mathrm{C}$. The next day, the cells were incubated with Alexa Fluor 488 goat antimouse IgG (1:500; Thermo Fisher Scientific) for $2 \mathrm{~h}$ at RT in the dark. Finally, samples were incubated with Hoechst 33258 (5 $\mathrm{\mu g} / \mathrm{mL}$; Sigma) for $15 \mathrm{~min}$ at RT. ZnO NG arrays and control glass coverslips with stained cells were mounted using ProLong Antifade (Thermo Fisher Scientific) and evaluated with a CLSM (Olympus).

\subsection{Immunofluorescence Detection of Sarcomeric $\alpha$-Actinin on C2C12 Cells}

Myoblast differentiation was determined by an immunodetection of sarcomeric $\alpha$ actinin after 7 days in a differentiation culture medium. A total of $1 \times 10^{5} \mathrm{C} 2 \mathrm{C} 12$ cells were seeded on ZnO NG arrays and glass coverslip controls. After 7 days in culture, the cells were fixed in $4 \%$ PFA in PBS for 15 min at RT, permeabilised with $0.1 \%$ Triton X-100 (Sigma) in PBS for $15 \mathrm{~min}$ and blocked for $20 \mathrm{~min}$ with 1\% bovine serum albumin (BSA; Sigma) in PBS at RT. Samples were then incubated with mouse anti-sarcomeric $\alpha$-actinin IgG monoclonal-antibody (1:500; Abcam) for $1 \mathrm{~h}$ at RT and washed with 1\% BSA-PBS. Then, the samples were incubated with Alexa Fluor 488 goat anti-mouse IgG (1:500) for $45 \mathrm{~min}$ at RT in the dark. Finally, the samples were incubated with Hoechst $33258(5 \mu \mathrm{g} / \mathrm{mL})$ for $15 \mathrm{~min}$ at RT. ZnO NG arrays and control glass coverslips with stained cells were mounted using ProLong Antifade and evaluated with a CLSM.

\subsection{Quantification of Inflammatory Cytokines Secretion}

THP-1 cells differentiated into macrophages were used to conduct this analysis. $\mathrm{ZnO}$ NG arrays were sterilized and placed over a culture of macrophages and maintained in contact with the cells for 5 and $24 \mathrm{~h}$. After each time-point, supernatants were removed and used to quantify cytokines secretion. Six inflammatory cytokines, IL-8, IL-12p70, IL-10, IL-6, 
IL-1 $\beta$ and TNF, were evaluated by flow cytometry using a CBA (Becton Dickinson, Franklin Lakes, NJ, USA). Cytokine concentration in the supernatant was analysed according to manufacturer's protocol. A positive control with $1 \mu \mathrm{g} / \mathrm{mL}$ of LPS (Sigma) and a negative control were performed together with samples analysis.

\subsection{Intracellular Calcium Quantification}

A7r5 cells were cultured on samples for $24 \mathrm{~h}$ and C2C12 cells were cultured on samples for 7 days in differentiation medium. Then, the cells were loaded with $2 \mu \mathrm{M}$ Fluo- 4 AM (Life Technologies, Carlsbad, CA, USA) in serum free DMEM for $30 \mathrm{~min}$ in the dark at RT. The samples were washed with serum-free DMEM and transferred to MatTek dishes with a fresh medium without phenol red. Images were captured using an Olympus IX71 inverted microscope equipped with epifluorescence and heating plate. A time-lapse every $1 \mathrm{~s}$ was recorded for 15 min for each sample (Video S1 in Supporting Information). Changes in fluorescent intensity during the time of monitoring were processed and quantified using Image J software (NIH).

\subsection{Statistical Analysis}

The quantitative data were presented as the mean with the standard error of the mean. Cell viability and percentage of activated cells were analysed using Fisher's exact test. The number of cells adhered and the spreading area of the cells were analysed using a t-test. Statistical comparisons of cytokine release were performed using the one-way analysis of variance (ANOVA) with Tukey's multiple comparisons test. All statistical analyses were performed with the GraphPad PRISM software (6.01).

\section{Conclusions}

In this study, we demonstrated the biocompatibility of ZnO NGs for smooth muscle cells and skeletal muscle cells. Both cell types were able to adhere, proliferate and differentiate on $\mathrm{ZnO}$ NGs. In addition, the ions released over time from the NGs did not affect the viability of muscle cells and did not induce an in vitro inflammatory response. Regarding the piezoelectric stimulation, the electromechanical interaction of NGs and cells was able to stimulate smooth muscle cells by inducing intracellular calcium transients, but no effect was observed on skeletal muscle cells. In single skeletal myotubes, the ZnO NGs simultaneously stimulate different regions of the cell randomly, and the lack of a unidirectional electric field interferes with contraction. The different response of two muscle cell types to the same ZnO NG indicates that the NG distribution and morphology should be custom designed and optimized according to the potential tissue of application. Although the use of electrical stimulation on muscle cells has been extensively studied, the effect of local electric fields at a cell-scale without applying external stimulation has a high upcoming potential. The work herein paves the way for future NG development able to stimulate muscle cells by local electrical impulses.

Supplementary Materials: The following are available online at https:/ /www.mdpi.com/article/10 $.3390 /$ ijms23010432/s1.

Author Contributions: Conceptualization, G.M. and A.B.; methodology, G.M., J.E., E.I. and A.B.; software, G.M.; validation, G.M., O.C., L.A.-V., A.A. and A.B.; formal analysis, L.A.-V. and A.A.; investigation, G.M., O.C., L.A.-V., A.A. and A.B.; resources, G.M. and C.N.; data curation, G.M., O.C., L.A.-V., A.A. and A.B.; writing-original draft preparation, G.M., A.B. and C.N.; writing-review and editing, G.M., A.B., E.I. and C.N.; supervision, G.M. and C.N.; project administration, G.M.; funding acquisition, G.M. and C.N. All authors have read and agreed to the published version of the manuscript.

Funding: This study was supported by the Spanish Government (MAT2017-86357-C3-3-R, PID2020118644RB-C21, PID2020-119350RA-I00 and EUR2020-112082), La Caixa Foundation under the Junior Leader Retaining program (LCF/BQ/PR19/11700010) and the Generalitat de Catalunya (2017-SGR503 and 2017-SGR-1420). 
Institutional Review Board Statement: Not applicable.

Informed Consent Statement: Not applicable.

Data Availability Statement: Data is contained within the article or Supplementary Material.

Acknowledgments: The authors would like to thank the staff from the Servei de Microscòpia of Universitat Autònoma de Barcelona and the cleanroom at the Institute of Microelectronics of Barcelona (IMB-CNM, CSIC).

Conflicts of Interest: The authors declare no conflict of interest. The funders had no role in the design of the study; in the collection, analyses, or interpretation of data; in the writing of the manuscript; or in the decision to publish the results.

\section{References}

1. Marino, A.; Arai, S.; Hou, Y.; Sinibaldi, E.; Pellegrino, M.; Chang, Y.T.; Mazzolai, B.; Mattoli, V.; Suzuki, M.; Ciofani, G. Piezoelectric Nanoparticle-Assisted Wireless Neuronal Stimulation. ACS Nano 2015, 9, 7678-7689. [CrossRef] [PubMed]

2. Badami, V.; Ahuja, B. Biosmart materials: Breaking new ground in dentistry. Sci. World J. 2014, 2014, 986912. [CrossRef] [PubMed]

3. Ribeiro, C.; Correia, D.M.; Ribeiro, S.; Sencadas, V.; Botelho, G.; Lanceros-Méndez, S. Piezoelectric poly(vinylidene fluoride) microstructure and poling state in active tissue engineering. Eng. Life Sci. 2015, 15, 351-356. [CrossRef]

4. Vargas-Estevez, C.; Blanquer, A.; Dulal, P.; Pérez del Real, R.; Duch, M.; Ibáñez, E.; Barrios, L.; Murillo, G.; Torras, N.; Nogués, C.; et al. Study of Galfenol direct cytotoxicity and remote microactuation in cells. Biomaterials 2017, 139, 67-74. [CrossRef]

5. Vargas-Estevez, C.; Blanquer, A.; Murillo, G.; Duque, M.; Barrios, L.; Nogués, C.; Ibañez, E.; Esteve, J. Electrical stimulation of cells through photovoltaic microcell arrays. Nano Energy 2018, 51, 571-578. [CrossRef]

6. Murillo, G.; Rodríguez-Ruiz, I.; Esteve, J. Selective Area Growth of High-Quality ZnO Nanosheets Assisted by Patternable AlN Seed Layer for Wafer-Level Integration. Cryst. Growth Des. 2016, 16, 5059-5066. [CrossRef]

7. Zhang, R.; Huang, Q.; Liu, X.; Yang, X.; Yan, H.; Xiong, Z.; Xu, N.; Ma, J.; Feng, Q.; Shen, Z. ZnO nanostructures enhance the osteogenic capacity of SaOS-2 cells on acid-etched pure Ti. Mater. Lett. 2018, 215, 173-175. [CrossRef]

8. Laurenti, M.; Cauda, V. ZnO Nanostructures for Tissue Engineering Applications. Nanomaterials 2017, 7, 374. [CrossRef] [PubMed]

9. Lin, P.H.; Sermersheim, M.; Li, H.; Lee, P.H.U.; Steinberg, S.M.; Ma, J. Zinc in wound healing modulation. Nutrients 2018, 10, 16. [CrossRef] [PubMed]

10. Su, Y.; Cockerill, I.; Wang, Y.; Qin, Y.-X.; Chang, L.; Zheng, Y.; Zhu, D. Zinc-Based Biomaterials for Regeneration and Therapy. Trends Biotechnol. 2019, 37, 428-441. [CrossRef]

11. Sánchez-Salcedo, S.; Shruti, S.; Salinas, A.J.; Malavasi, G.; Menabue, L.; Vallet-Regí, M. In vitro antibacterial capacity and cytocompatibility of $\mathrm{SiO}_{2}-\mathrm{CaO}-\mathrm{P}_{2} \mathrm{O}_{5}$ meso-macroporous glass scaffolds enriched with ZnO. J. Mater. Chem. B 2014, 2, $4836-4847$. [CrossRef]

12. Colon, G.; Ward, B.C.; Webster, T.J. Increased osteoblast and decreasedStaphylococcus epidermidis functions on nanophase ZnO and $\mathrm{TiO}_{2}$. J. Biomed. Mater. Res. Part A 2006, 78, 595-604. [CrossRef]

13. Saha, N.; Dubey, A.K.; Basu, B. Cellular proliferation, cellular viability, and biocompatibility of HA-ZnO composites. J. Biomed. Mater. Res.-Part B Appl. Biomater. 2012, 100, 256-264. [CrossRef] [PubMed]

14. Lee, J.; Kang, B.S.; Hicks, B.; Chancellor, T.F.; Chu, B.H.; Wang, H.-T.; Keselowsky, B.G.; Ren, F.; Lele, T.P. The control of cell adhesion and viability by zinc oxide nanorods. Biomaterials 2008, 29, 3743-3749. [CrossRef] [PubMed]

15. Zaveri, T.D.; Dolgova, N.V.; Chu, B.H.; Lee, J.; Wong, J.; Lele, T.P.; Ren, F.; Keselowsky, B.G. Contributions of surface topography and cytotoxicity to the macrophage response to zinc oxide nanorods. Biomaterials 2010, 31, 2999-3007. [CrossRef] [PubMed]

16. Park, J.K.; Kim, Y.J.; Yeom, J.; Jeon, J.H.; Yi, G.C.; Je, J.H.; Hahn, S.K. The topographic effect of zinc oxide nanoflowers on osteoblast growth and osseointegration. Adv. Mater. 2010, 22, 4857-4861. [CrossRef]

17. Wang, Y.; Wu, Y.; Quadri, F.; Prox, J.; Guo, L. Cytotoxicity of ZnO Nanowire Arrays on Excitable Cells. Nanomaterials 2017, 7, 80. [CrossRef] [PubMed]

18. Murillo, G.; Blanquer, A.; Vargas-Estevez, C.; Barrios, L.; Ibáñez, E.; Nogués, C.; Esteve, J. Electromechanical Nanogenerator-Cell Interaction Modulates Cell Activity. Adv. Mater. 2017, 29, 1605048. [CrossRef]

19. Park, I.; Hong, Y.; Jun, Y.-H.; Lee, G.-Y.; Jun, H.-S.; Pyun, J.-C.; Choi, J.-W.; Cho, S. Electrical Impedance Monitoring of C2C12 Myoblast Differentiation on an Indium Tin Oxide Electrode. Sensors 2016, 16, 2068. [CrossRef]

20. Park, H.; Bhalla, R.; Saigal, R.; Radisic, M.; Watson, N.; Langer, R.; Vunjak-Novakovic, G. Effects of electrical stimulation in C2C12 muscle constructs. J. Tissue Eng. Regen. Med. 2008, 2, 279-287. [CrossRef]

21. Ganz, A.; Lambert, M.; Saez, A.; Silberzan, P.; Buguin, A.; Mège, R.M.; Ladoux, B. Traction forces exerted through N-cadherin contacts. Biol. Cell 2006, 98, 721-730. [CrossRef]

22. Ladoux, B.; Anon, E.; Lambert, M.; Rabodzey, A.; Hersen, P.; Buguin, A.; Silberzan, P.; Mège, R.M. Strength dependence of cadherin-mediated adhesions. Biophys. J. 2010, 98, 534-542. [CrossRef] [PubMed]

23. Tsai, M.S.; Chiang, M.T.; Tsai, D.L.; Yang, C.W.; Hou, H.S.; Li, Y.R.; Chang, P.C.; Lin, H.H.; Chen, H.Y.; Hwang, I.S.; et al. Galectin-1 Restricts Vascular Smooth Muscle Cell Motility via Modulating Adhesion Force and Focal Adhesion Dynamics. Sci. Rep. 2018, 8 , 11497. [CrossRef] 
24. Mestre, R.; Patiño, T.; Barceló, X.; Anand, S.; Pérez-Jiménez, A.; Sánchez, S. Force Modulation and Adaptability of 3D-Bioprinted Biological Actuators Based on Skeletal Muscle Tissue. Adv. Mater. Technol. 2019, 4, 1800631. [CrossRef]

25. Valdiglesias, V.; Costa, C.; Kiliç, G.; Costa, S.; Pásaro, E.; Laffon, B.; Teixeira, J.P. Neuronal cytotoxicity and genotoxicity induced by zinc oxide nanoparticles. Environ. Int. 2013, 55, 92-100. [CrossRef] [PubMed]

26. Ma, J.; Zhao, N.; Zhu, D. Bioabsorbable zinc ion induced biphasic cellular responses in vascular smooth muscle cells. Sci. Rep. 2016, 6, 26661. [CrossRef]

27. Berger, M. Zinc reduces intimal hyperplasia in the rat carotid injury model. Atherosclerosis 2004, 175, 229-234. [CrossRef]

28. Wang, W.; Poh, C.K. Titanium Alloys in Orthopaedics. Titan. Alloys-Adv. Prop. Control 2013, 15, 1-20. [CrossRef]

29. Salucci, S.; Baldassarri, V.; Falcieri, E.; Burattini, S. $\alpha$-Actinin involvement in Z-disk assembly during skeletal muscle C2C12 cells in vitro differentiation. Micron 2014, 68, 47-53. [CrossRef]

30. Ciofani, G.; Genchi, G.G.; Mattoli, V. ZnO nanowire arrays as substrates for cell proliferation and differentiation. Mater. Sci. Eng. C 2012, 32, 341-347. [CrossRef]

31. Kitsara, M.; Blanquer, A.; Murillo, G.; Humblot, V.; De Bragança Vieira, S.; Nogués, C.; Ibáñez, E.; Esteve, J.; Barrios, L. Permanently hydrophilic, piezoelectric PVDF nanofibrous scaffolds promoting unaided electromechanical stimulation on osteoblasts. Nanoscale 2019, 11, 8906-8917. [CrossRef] [PubMed]

32. Ito, A.; Yamamoto, Y.; Sato, M.; Ikeda, K.; Yamamoto, M.; Fujita, H.; Nagamori, E.; Kawabe, Y.; Kamihira, M. Induction of functional tissue-engineered skeletal muscle constructs by defined electrical stimulation. Sci. Rep. 2014, 4, 4781. [CrossRef] [PubMed]

33. Morabito, C.; Rovetta, F.; Bizzarri, M.; Mazzoleni, G.; Fanò, G.; Mariggiò, M.A. Modulation of redox status and calcium handling by extremely low frequency electromagnetic fields in C2C12 muscle cells: A real-time, single-cell approach. Free Radic. Biol. Med. 2010, 48, 579-589. [CrossRef] [PubMed]

34. Martins, P.M.; Ribeiro, S.; Ribeiro, C.; Sencadas, V.; Gomes, A.C.; Gama, F.M.; Lanceros-Méndez, S. Effect of poling state and morphology of piezoelectric poly(vinylidene fluoride) membranes for skeletal muscle tissue engineering. RSC Adv. 2013, 3, 17938. [CrossRef]

35. Epstein, B.R.; Foster, K.R. Anisotropy in the dielectric properties of skeletal muscle. Med. Biol. Eng. Comput. 1983, 21, 51-55. [CrossRef] [PubMed]

36. Yamasaki, K.; Hayashi, H.; Nishiyama, K.; Kobayashi, H.; Uto, S.; Kondo, H.; Hashimoto, S.; Fujisato, T. Control of myotube contraction using electrical pulse stimulation for bio-actuator. J. Artif. Organs 2009, 12, 131-137. [CrossRef] [PubMed] 